\title{
Fitting of Probability Distribution on the Post-Monsoon Rainfall of Different Locations in Bangladesh
}

\author{
Md. Habibur Rahman ${ }^{1}$ \\ ${ }^{1}$ Department of Statistics, Jahangirnagar University, Bangladesh \\ Correspondence: Md. Habibur Rahman, Department of Statistics, Jahangirnagar University, Dhaka-1342, \\ Bangladesh. E-mail: habib.drj@juniv.edu, habib.drj@gmail.com
}

Received: March 18, 2019

Accepted: April 20, 2019

Online Published: April 29, 2019

doi:10.5539/enrr.v9n2p27

URL: https://doi.org/10.5539/enrr.v9n2p27

\begin{abstract}
Different probability distributions of post-monsoon rainfall of different locations in Bangladesh are fitted. It is found that, for the data, Weibull distribution for Barisal, Bogra, Chittagong, Comilla, Cox's Bazar, Faridpur, Jessore, Khulna, Maijdi Court, Mymensingh, Satkhira, and Sylhet; the Gamma distribution for Dhaka, Ishurdi, Rangamati, Rangpur, and Srimangal based on graphical assessment and goodness-of-fit criterion. In this study, different probability distributions have been fitted for the data of post-monsoon precipitation for 17 different locations in Bangladesh over the period 1961-2014.
\end{abstract}

Keywords: Cumulative Distribution, Cramer-von Mise, Anderson-Darling, AIC, BIC

\section{Introduction}

It is expected that Bangladesh, like many other countries, experiences variations in the climate variables over the years. However, the knowledge about the nature or feature of these variables is very important to facilitate in unearthing the hidden information that may have significant policy implications in both short and long-run perspectives in a country. The term climate is referred to the average state of the atmosphere near the earth's surface over a long span of time that includes the temperature, precipitation, humidity, air pressure, wind movement, and wind direction. The Geographical location (latitude, coastal or continental position) and the physical settings (e.g. mountains) of a country influence the climate of the country. Bangladesh extends from $20^{\circ} 34^{\prime} \mathrm{N}$ to $26^{\circ} 38^{\prime} \mathrm{N}$ latitude and from $88^{\circ} 01^{\prime} \mathrm{E}$ to $92^{\circ} 41^{\prime} \mathrm{E}$ longitude bordered by the Himalayas to the north and by the Bay of Bengal to the south. The fitting distribution to rainfall data is one of the very frequent tasks that choose probability distribution to model a random variable along with the estimates of the parameter(s) of the chosen distribution under efficient expertise and valid judgment, which generally necessitates iterative process of distribution choice, parameter estimation, and determining quality-of-fit assessment. It is thus found interest in the field of meteorology (for any atmospheric parameter) to provide a good fit of rainfall data which strongly depends on the fitting of the probability distribution. The Akaike information criterion and Bayesian information criterion is used to develop a package to fit different distributions (Delignette-Muller et al., 2015). The R program for Package 'glogis' for fitting and testing generalized logistic distribution is written by Zeileis et al. (2014). The annual maximum of daily rainfall in Japan has been fitted with Weibull distribution as the best-fitted distribution (Hirose, 1994). Sharma and Singh (2010) analyzed the daily maximum rainfall data of Pantnagar, India for a period of 37 years and the best-fitted probability distribution identified using the least squares method from among the 16 compared distributions. Lee (2005) pointed out that the log-Pearson type III distribution fitted for fifty percent of the total stations for the rainfall distribution characteristics of Chia-Nan plain area. The annual maxima of daily rainfall for five locations in South Korea for the years 1961-2001 through fitting the generalized extreme value distribution have studied and observed that the Gumbel distribution provided the most reasonable model for four of the five locations considered (Nadarajah et al., 2007). Bhakar et al. (2006) observed the frequency analysis of consecutive-day-peaked-rainfall at Banswara, Rajasthan in India and found gamma distribution as the best fitted compared to other distributions tested by the Chi-square test. The extreme value distribution was fitted to the rainfall data over fourteen locations in West Florida and sixteen locations spread throughout New Zealand (Nadarajah \& Withers, 2001; Nadarajah, 2005). Deka et al. (2009) have provided the best-fitted probability distribution to describe the annual series of maximum rainfall data for the period of 42 years of nine distantly located stations in north-east India considering only five extreme value distributions. 
Annual rainfall data for fourteen rainfall stations in Sudan for the period 1971 to 2010 were analyzed where normal distribution and gamma distribution were found to be the best-fitted probability distributions (Mahgoub et al., 2016). Rahman (2017) applied Ward's hierarchical agglomerative clustering technique to analyze the pre-monsoon precipitation of Bangladesh. The spatial and temporal distribution of rainfall intensity at local scale has studied by Redano and Lorente (1993).

To fit the probability distribution for rainfall data of different locations in Bangladesh is very important in order to help the planners in formulating significant policy matters. Hossian et al. (2016) fits several types of probability distributions for the climate parameter of monthly-maximum-temperature of Dhaka, Bangladesh and found the generalized skew logistic distribution as the best-fitted one. Rahman and Lateh (2016) have been focused on assessing and analyzing meteorological drought characteristics of Bangladesh based on rainfall, standardized precipitation index and geographic information system for the period of 1971-2010. The empirical distribution pattern and hierarchical clustering technique are used to find homogeneous region based on precipitation of different region in Bangladesh (Rahman et al., 2018). Arora et al. (2006) studied the spatial distribution and seasonal variability of the rainfall in a mountainous Basin in the Himalayan Region. Ghosh et al. (2016) found the generalized extreme value distribution empirically provided the best-fitted distribution for the monthly rainfall data for Chittagong, Rajshahi, Sylhet and the gamma distribution for Dhaka.

This study aims at to fit and select the best-fitted probability distribution for post-monsoon (October-November) rainfall data of 17 locations for the period 1961-2014 in Bangladesh. In doing so, the normal distribution with parameters mean and standard deviation, Weibull distribution with parameters shape and scale, Gamma distribution with parameters shape and rate, lognormal distribution with parameters log mean and log standard deviation, exponential distribution with parameter rate, Cauchy distribution with location and scale, and logistic distribution with parameters location and scale will be fitted while the parameters of the distributions are estimated through iterative maximum likelihood method and the findings are discussed in terms of probability density along with the histogram, cumulative distribution function, and Q-Q plot. The moment matching estimation, quantile matching estimation and maximum goodness-of-fit estimation may also be used instead of maximum likelihood method. However, the quality-of-fit of the probability distribution will be tested by the goodness-of-fit statistic the Anderson-Darling (AD), Cramer-von Mise (CvM), Kolmogorov-Smirnov (KS) and will be judged by the value of the log-likelihood, Akaike information criterion (AIC), and Bayesian information criterion (BIC).

The main objectives of this study are - to reveal the nature of post-monsoon rainfall of different locations, to fit the fit the probability distributions to post-monsoon rainfall, to check the quality-of-fit of the probability distribution by the goodness-of-fit statistic, and to find the best-fitted distribution of post-monsoon rainfall for each location. In this analysis especially in fitting probability distributions, the following steps will be implemented - Collecting of Data of interest and exploratory data analysis is such as visualization, detection of outlier, trimming etc., the data must be taken into the streamline, also as well as summarized, Several descriptive measures are used to reveal the nature of the data, Fit the probability distributions for post-monsoon rainfall of different locations, Check the accuracy of fitted probability distribution, and Evaluate the best-fitted distribution based on Akaike information criterion (AIC), and Bayesian information criterion (BIC). For this study, the data on the rainfall 17 different locations have been collected from the Bangladesh Meteorological Department. These data are generated from the available atmospheric data record stations in Bangladesh for the period 1961-2014.

This study is organized into different sections including this section. The second section reviews the theory and the methodology of different techniques related to fit the probability distribution. In this section, the basic concepts of the different probability distribution, cumulative distribution of probability distributions are discussed. Also in this chapter, the different goodness-of-fit tests for fitted probability distributions are talked about. The third section focuses on the computational issues and results of the fitted probability distributions. As well as the discussion about the results are presented in this section. A summary with some concluding remarks and some suggestions for further research is contained in the final section.

\section{Theory behind the Study: Fitting of Probability Distributions}

A lot of probability distribution functions have been proposed in recent past, but in present study Weibull, Lognormal, Gamma and others are used to describe the characteristics of rainfall. Parameters defining each distribution function are calculated using maximum likelihood method. The probability density function (PDF) of the Weibull distribution with two parameters is given by Weibull (1951). The Lognormal distribution is a probability distribution of a random variable whose logarithm is normally distributed. The probability density 
function (PDF) of the lognormal distribution is given by Johnson et al. (1994). Lancaster (1966) quotes from Laplace in which the latter obtains a Gamma distribution.

\subsection{Cumulative Distribution Function}

As indicated at the end of the introduction this study will use the widely used the normal, Weibull, Gamma, lognormal, logistic, and exponential distributions to fit the post-monsoon rainfall (in $\mathrm{mm}$ ) of 17 different locations in Bangladesh albeit the extensive literature experienced the use of many probability distributions in recent past. In doing so, the cumulative distribution functions of the considered probability densities are needed. They are given in Table 1 along with their parameters involve along with some remarks on them

Table 1 Cumulative distribution function with parameters of the probability density functions in this study.

\begin{tabular}{|c|c|c|c|}
\hline Distribution & Cumulative Distribution Function & Parameter & Remarks \\
\hline Cauchy & $F(x)=\frac{1}{2}+\frac{1}{\pi} \tan ^{-1}\left(\frac{x-\mu}{\sigma}\right)$ & $\begin{array}{l}\mu: \text { Location parameter } \\
\sigma: \text { Scale parameter }\end{array}$ & \\
\hline Exponential & $F(x)=1-\exp [-\lambda(x-\gamma)]$ & $\begin{array}{l}\gamma: \text { Location parameter } \\
\lambda: \text { Inverse scale parameter }\end{array}$ & \\
\hline Gamma & $F(x)=\frac{\Gamma_{((x-\gamma) / \beta)}(\alpha)}{\Gamma(\alpha)}$ & $\begin{array}{l}\gamma: \text { Location parameter } \\
\beta: \text { Scale parameter } \\
\alpha: \text { Shape parameter }\end{array}$ & $\begin{array}{c}\Gamma_{z}: \text { Incomplete gamma function } \\
\gamma=0 \text { yields two parameter } \\
\text { Gamma distribution }\end{array}$ \\
\hline Logistic & $F(x)=\left[1+\exp \left(\frac{x-\mu}{\sigma}\right)\right]^{-1}$ & $\begin{array}{l}\mu: \text { Location parameter } \\
\sigma: \text { Scale parameter }\end{array}$ & \\
\hline Lognormal & $F(x)=\Phi\left[\frac{\ln (x-\gamma)-\mu}{\sigma}\right]$ & $\begin{array}{l}\gamma: \text { Loaction parameter } \\
\mu: \text { Scale parameter } \\
\sigma: \text { Shape parameter }\end{array}$ & $\begin{array}{c}\gamma=0 \text { yields two parameter } \\
\text { Lognormal distribution }\end{array}$ \\
\hline Normal & $F(x)=\Phi\left(\frac{x-\mu}{\sigma}\right)$ & $\begin{array}{l}\mu: \text { Location parameter } \\
\sigma: \text { Scale parameter }\end{array}$ & $\begin{array}{l}\text { Laplace integral } \\
\Phi(z)=(\sqrt{2 \pi})^{-1} \int_{0}^{z} e^{-t^{2} / 2} d t\end{array}$ \\
\hline Weibull & $F(x)=1-\exp \left[-\left(\frac{x-\gamma}{\beta}\right)^{\alpha}\right]$ & $\begin{array}{l}\gamma: \text { Location parameter } \\
\beta: \text { Scale parameter } \\
\alpha: \text { Shape parameter }\end{array}$ & $\begin{array}{l}\gamma=0 \text { yields the two-parameter } \\
\text { Weibull distribution }\end{array}$ \\
\hline
\end{tabular}

\subsection{Goodness-of-fit Tests}

To evaluate the goodness-of-fit of the probability distributions functions fitted for the post-monsoon rainfall data of 17 different locations in Bangladesh will be tested by the Anderson-Darling (AD), Cramer-von Mise (CvM) and Kolmogorov-Smirnov (KS) test statistic and will be judged by the value of the log-likelihood, Akaike information criterion (AIC), and Bayesian information criterion (BIC) (Table 2). 
Table 2. Goodness of fit Statistic

\begin{tabular}{lll}
\hline Statistic & General Formula & Computational Formula \\
\hline$n \int_{-\infty}^{\infty} \frac{\left[F_{n}(x)-F(x)\right]^{2}}{F(x)[1-F(x)]} d x$ & $-n-\frac{1}{n} \sum_{i=1}^{n}(2 i-1) \log \left[F_{i}\left(1-F_{n+1-i}\right)\right]$ \\
Anderson-Darling (AD) & where $F_{i} \triangleq F\left(x_{i}\right)$ \\
$\qquad \int_{-\infty}^{\infty}\left[F_{n}(x)-F(x)\right]^{2} d x$ & $\frac{1}{12 n}+\sum_{i=1}^{n}\left(F_{i}-\frac{2 i-1}{n}\right)^{2}$ \\
Cramer-von Mise (CvM) & $\max \left(D^{+}, D^{-}\right)$with \\
Kolmogorov-Smirnov (KS) & $D^{+}=\max _{i=1, \ldots, n}\left(\frac{i}{n}-F_{i}\right)$ \\
& $\sup \left|F_{n}(x)-F(x)\right|$ & and $D^{-}=\max _{i=1, \ldots, n}\left(F_{i}-\frac{i-1}{n}\right)$
\end{tabular}

\section{Results and Discussions}

In fitting the probability distributions the normal with parameters mean and standard deviation, Weibull with parameters shape and scale, Gamma with parameters shape and rate, lognormal with parameters log mean and log standard deviation, exponential with parameter rate, and Cauchy and logistic with parameters location and scale are used for the post-monsoon rainfall data of 17 different locations in Bangladesh; while the parameters of the distributions are estimated through iterative maximum likelihood method and the findings are presented in Figure 2 to Figure 6 to see the fitting in terms of probability density with the histogram, cumulative distribution function, and P-P plot.

\subsection{Data Description}

The rainfall (in $\mathrm{mm}$ ) of post-monsoon (October-November) for the years 1961 through 2014 are taken into consideration to fit the probability distribution. The rainfall (in $\mathrm{mm}$ ) were recorded at the 17 different locations (latitude, longitude) - Barisal (22.72, 90.37), Bogra (24.85, 89.37), Chittagong (22.35, 91.82), Comilla (23.43, 91.18), Cox's Bazar (21.45, 91.97), Dhaka (23.78, 90.38), Faridpur (23.93, 89.85), Ishurdi $(24.15,89.03)$, Jessore $(23.20$, 89.33), Khulna $(22.78,89.53)$, Maijdi Court (22.87, 91.10), Mymensingh (24.73, 90.42), Rangamati (22.63, 92.15), Rangpur (25.73, 89.27), Satkhira (22.72, 89.08), Srimangal $(24.3,91.7)$ and Sylhet $(24.9,91.88)$ by the Bangladesh Meteorological Department during 1961 to 2014. In order to have the better understanding of the rainfall data, before entering into the desired analysis, the summary statistics for the data may be explored first.

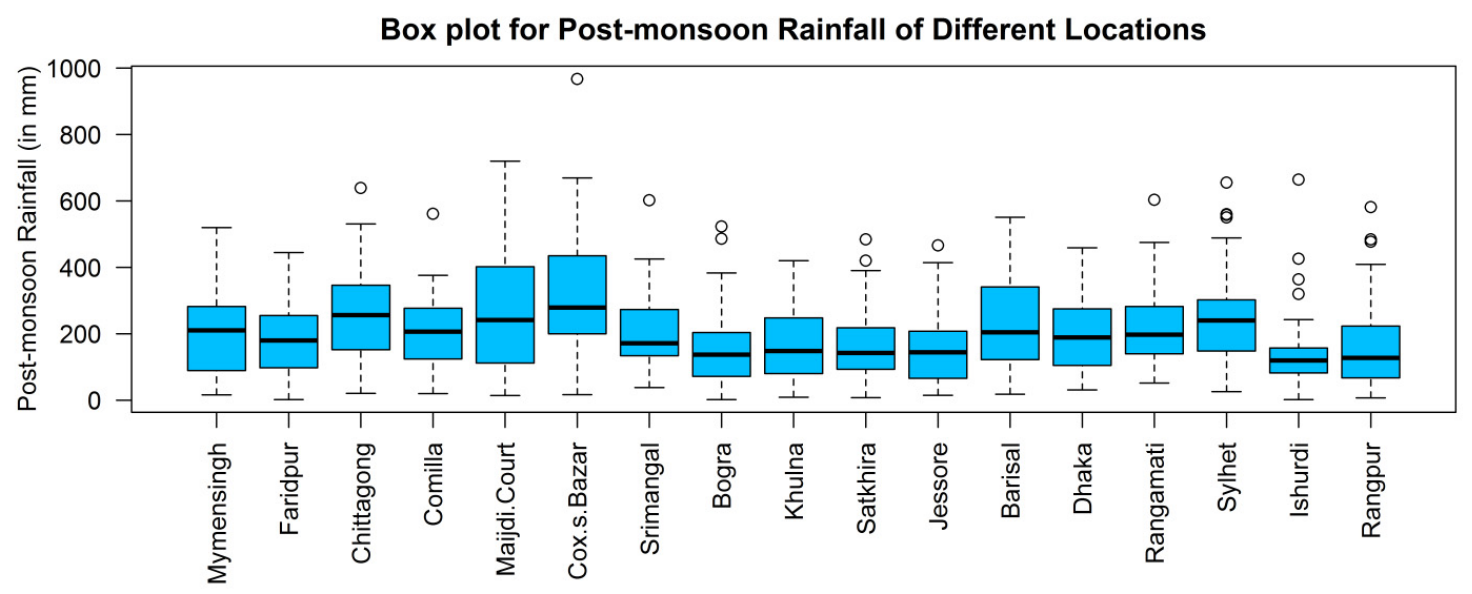

Figure 1. Box-and-Whisker plots of the rainfall (in mm) of Post-monsoon of 17 different locations in Bangladesh 
Table 3. Summary Statistics for post-monsoon rainfall of the 17 locations in Bangladesh

\begin{tabular}{|c|c|c|c|c|c|c|c|c|c|}
\hline 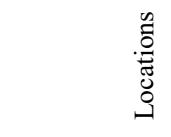 & 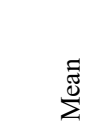 & 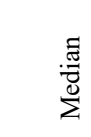 & $\frac{\pi}{8}$ & 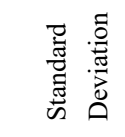 & $\begin{array}{l}\frac{n}{0} \\
0 \\
0 \\
0 \\
1\end{array}$ & 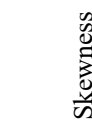 & $\begin{array}{l}\stackrel{8}{\infty} \\
\stackrel{\Xi}{\approx} \\
\simeq\end{array}$ & & \\
\hline Mymensingh & 204.8 & 210.5 & 242 & 141.7 & -0.24 & 0.66 & 504 & 16 & 520 \\
\hline Faridpur & 185.3 & 180.0 & 56 & 104.6 & -0.23 & 0.45 & 443 & 2 & 445 \\
\hline Chittagong & 259.1 & 256.5 & 234 & 136.2 & -0.11 & 0.33 & 618 & 21 & 639 \\
\hline Comilla & 204.5 & 206.5 & 98 & 112.2 & 0.47 & 0.45 & 541 & 20 & 561 \\
\hline Maijdi Court & 266.6 & 241.5 & 187 & 174.0 & -0.06 & 0.64 & 706 & 14 & 720 \\
\hline Cox's Bazar & 316.2 & 279.0 & 204 & 177.6 & 2.10 & 1.00 & 950 & 17 & 967 \\
\hline Srimangal & 198.1 & 171.5 & 207 & 110.3 & 2.18 & 1.15 & 564 & 38 & 602 \\
\hline Bogra & 151.0 & 137.5 & 62 & 107.6 & 3.03 & 1.50 & 521 & 2 & 523 \\
\hline Khulna & 164.3 & 148.5 & 78 & 101.7 & -0.70 & 0.37 & 411 & 9 & 420 \\
\hline Satkhira & 168.8 & 142.5 & 189 & 111.3 & 0.33 & 0.91 & 476 & 8 & 484 \\
\hline Jessore & 155.7 & 144.5 & 65 & 102.3 & 0.99 & 0.91 & 451 & 15 & 466 \\
\hline Barisal & 228.4 & 204.5 & 343 & 131.8 & -0.66 & 0.40 & 533 & 18 & 551 \\
\hline Dhaka & 197.8 & 189.0 & 189 & 113.7 & -0.48 & 0.63 & 428 & 31 & 459 \\
\hline Rangamati & 225.0 & 197.5 & 264 & 116.6 & 0.91 & 0.91 & 551 & 52 & 603 \\
\hline Sylhet & 244.0 & 240.0 & 188 & 147.3 & 0.43 & 0.81 & 629 & 26 & 655 \\
\hline Ishurdi & 139.2 & 119.5 & 208 & 108.3 & 10.30 & 2.71 & 662 & 2 & 664 \\
\hline Rangpur & 163.7 & 127.5 & 106 & 128.6 & 1.59 & 1.34 & 574 & 7 & 581 \\
\hline
\end{tabular}

The maximum rainfall occurs in Cox's Bazar $(967 \mathrm{~mm})$ and minimum rainfall occurs in Faridpur, Bogra and Ishurdi $(2 \mathrm{~mm}$ ) for the post-monsoon season (Table 3). The box-and-whisker plots demonstrate that outliers were present in the series of the post-monsoon rainfall data for different locations except for Barisal, Dhaka, Faridpur, Khulna, Maijdi Court and Mymensingh. The post-monsoon rainfall data pattern of Cox's Bazar, Barisal and Maijdi Court are different and are more variable than the other locations in Bangladesh (Figure 1).

\subsection{Fitted Parameter of Probability Distributions and Goodness of Fit Results}

The parameters of the distributions for the post-monsoon rainfall of 17 locations are estimated through iterative maximum likelihood method and the estimated parameters of the distributions are presented in Table 4. The Kolmogorov-Smirnov, Cramer-von Mises, and Anderson-Darling goodness of fit statistics are computed for the fitted probability distribution for the post-monsoon rainfall of different locations in Bangladesh and the best-fitted probability distributions are found for the minimum value of Akaike information criterion and Bayesian information criterion as the goodness of fit criteria.

Table 4. Estimated parameters of different PDFs for post-monsoon rainfall of the 17 locations in Bangladesh

\begin{tabular}{|c|c|c|c|c|c|c|c|}
\hline Distribution & Parameter & $\begin{array}{l}\text { Estimated } \\
\text { Parameter }\end{array}$ & $\begin{array}{l}\text { Standard } \\
\text { Error }\end{array}$ & $\begin{array}{l}\text { Estimated } \\
\text { Parameter }\end{array}$ & $\begin{array}{l}\text { Standard } \\
\text { Error }\end{array}$ & $\begin{array}{l}\text { Estimated } \\
\text { Parameter }\end{array}$ & $\begin{array}{l}\text { Standard } \\
\text { Error }\end{array}$ \\
\hline & & Mymensingh & & Satkhira & & Comilla & \\
\hline \multirow[t]{2}{*}{ Normal } & Mean & 204.796 & 19.098 & 168.778 & 15.002 & 204.482 & 15.132 \\
\hline & Standard deviation & 140.344 & 13.505 & 110.242 & 10.608 & 111.195 & 10.700 \\
\hline \multirow[t]{2}{*}{ Weibull } & Shape & 1.415 & 0.156 & 1.550 & 0.165 & 1.865 & 0.204 \\
\hline & Scale & 224.334 & 22.657 & 187.442 & 17.307 & 229.328 & 17.539 \\
\hline \multirow[t]{2}{*}{ Gamma } & Shape & 1.633 & 0.280 & 1.993 & 0.350 & 2.505 & 0.445 \\
\hline & Rate & 0.008 & 0.002 & 0.012 & 0.002 & 0.012 & 0.002 \\
\hline \multirow[t]{2}{*}{ Lognormal } & Log Mean & 4.986 & 0.129 & 4.857 & 0.115 & 5.108 & 0.102 \\
\hline & Log Standard Deviation & 0.945 & 0.091 & 0.849 & 0.082 & 0.751 & 0.072 \\
\hline Exponential & Rate & 0.005 & 0.001 & 0.006 & 0.001 & 0.005 & 0.001 \\
\hline Cauchy & Location & 190.053 & 19.204 & 134.067 & 14.040 & 201.879 & 15.359 \\
\hline
\end{tabular}




\begin{tabular}{|c|c|c|c|c|c|c|c|}
\hline & Scale & 84.654 & 14.713 & 60.810 & 10.676 & 69.544 & 12.021 \\
\hline \multirow[t]{3}{*}{ Logistic } & Location & 194.182 & 19.087 & 157.051 & 14.630 & 201.934 & 15.264 \\
\hline & Scale & 80.279 & 9.089 & 61.712 & 7.036 & 63.839 & 7.141 \\
\hline & & Faridpur & & Jessore & & Dhaka & \\
\hline \multirow[t]{2}{*}{ Normal } & Mean & 185.296 & 14.108 & 155.685 & 13.794 & 197.759 & 15.332 \\
\hline & Standard deviation & 103.675 & 9.976 & 101.366 & 9.754 & 112.664 & 10.841 \\
\hline \multirow[t]{2}{*}{ Weibull } & Shape & 1.770 & 0.195 & 1.554 & 0.167 & 1.852 & 0.198 \\
\hline & Scale & 206.697 & 16.629 & 173.033 & 15.944 & 223.517 & 17.343 \\
\hline \multirow[t]{2}{*}{ Gamma } & Shape & 2.234 & 0.395 & 1.991 & 0.351 & 2.880 & 0.517 \\
\hline & Rate & 0.012 & 0.002 & 0.013 & 0.003 & 0.015 & 0.003 \\
\hline \multirow[t]{2}{*}{ Lognormal } & Log Mean & 4.982 & 0.118 & 4.776 & 0.112 & 5.103 & 0.087 \\
\hline & Log Standard Deviation & 0.868 & 0.084 & 0.825 & 0.079 & 0.639 & 0.061 \\
\hline Exponential & Rate & 0.005 & 0.001 & 0.006 & 0.001 & 0.005 & 0.001 \\
\hline \multirow[t]{2}{*}{ Cauchy } & Location & 180.183 & 12.417 & 144.663 & 13.343 & 175.356 & 16.243 \\
\hline & Scale & 60.620 & 11.133 & 59.770 & 10.261 & 71.164 & 12.074 \\
\hline \multirow[t]{3}{*}{ Logistic } & Location & 180.653 & 14.239 & 148.337 & 13.303 & 188.585 & 15.676 \\
\hline & Scale & 59.767 & 6.740 & 56.194 & 6.352 & 65.446 & 7.355 \\
\hline & & Chittagong & & Barisal & & Maijdi Co & \\
\hline \multirow[t]{2}{*}{ Normal } & Mean & 259.074 & 18.360 & 228.426 & 17.764 & 266.556 & 23.454 \\
\hline & Standard deviation & 134.917 & 12.982 & 130.538 & 12.561 & 172.350 & 16.584 \\
\hline \multirow[t]{2}{*}{ Weibull } & Shape & 1.980 & 0.217 & 1.785 & 0.196 & 1.545 & 0.169 \\
\hline & Scale & 291.550 & 21.023 & 256.382 & 20.533 & 295.845 & 27.390 \\
\hline \multirow[t]{2}{*}{ Gamma } & Shape & 2.804 & 0.497 & 2.411 & 0.425 & 1.928 & 0.330 \\
\hline & Rate & 0.011 & 0.002 & 0.011 & 0.002 & 0.007 & 0.001 \\
\hline \multirow[t]{2}{*}{ Lognormal } & Log Mean & 5.368 & 0.095 & 5.210 & 0.102 & 5.304 & 0.115 \\
\hline & Log Standard Deviation & 0.696 & 0.067 & 0.749 & 0.072 & 0.848 & 0.082 \\
\hline Exponential & Rate & 0.004 & 0.0004 & 0.004 & 0.001 & 0.004 & 0.0004 \\
\hline \multirow[t]{2}{*}{ Cauchy } & Location & 256.411 & 18.215 & 200.757 & 20.433 & 236.453 & 25.136 \\
\hline & Scale & 84.302 & 14.770 & 87.276 & 15.116 & 111.067 & 18.996 \\
\hline \multirow[t]{3}{*}{ Logistic } & Location & 256.157 & 18.694 & 221.895 & 18.660 & 255.310 & 23.970 \\
\hline & Scale & 78.166 & 8.757 & 77.302 & 8.579 & 99.876 & 11.145 \\
\hline & & Rangamati & & Khulna & & Bogra & \\
\hline \multirow[t]{2}{*}{ Normal } & Mean & 225.019 & 15.719 & 164.278 & 13.713 & 151.019 & 14.510 \\
\hline & Standard deviation & 115.511 & 11.115 & 100.770 & 9.697 & 106.627 & 10.260 \\
\hline \multirow[t]{2}{*}{ Weibull } & Shape & 2.073 & 0.213 & 1.580 & 0.177 & 1.452 & 0.151 \\
\hline & Scale & 254.949 & 17.700 & 181.925 & 16.406 & 166.421 & 16.414 \\
\hline \multirow[t]{2}{*}{ Gamma } & Shape & 3.785 & 0.688 & 1.860 & 0.325 & 1.832 & 0.321 \\
\hline & Rate & 0.017 & 0.003 & 0.011 & 0.002 & 0.012 & 0.002 \\
\hline \multirow[t]{2}{*}{ Lognormal } & Log Mean & 5.278 & 0.074 & 4.809 & 0.123 & 4.720 & 0.125 \\
\hline & Log Standard Deviation & 0.545 & 0.052 & 0.907 & 0.087 & 0.919 & 0.088 \\
\hline Exponential & Rate & 0.004 & 0.001 & 0.006 & 0.001 & 0.007 & 0.001 \\
\hline Cauchy & Location & 197.175 & 16.659 & 144.407 & 16.503 & 127.479 & 14.599 \\
\hline & Scale & 69.492 & 11.838 & 68.838 & 11.671 & 58.170 & 9.485 \\
\hline Logistic & Location & 215.206 & 15.394 & 159.639 & 14.479 & 139.137 & 12.944 \\
\hline & Scale & 64.726 & 7.299 & 59.892 & 6.634 & 55.338 & 6.313 \\
\hline & & Cox's Baza & & Sylhet & & Rangpur & \\
\hline Normal & Mean & 316.241 & 23.943 & 243.982 & 19.853 & 163.741 & 17.344 \\
\hline & Standard deviation & 175.946 & 16.930 & 145.887 & 14.038 & 127.449 & 12.264 \\
\hline Weibull & Shape & 1.852 & 0.193 & 1.719 & 0.183 & 1.321 & 0.139 \\
\hline & Scale & 355.365 & 27.469 & 273.558 & 22.791 & 178.161 & 19.353 \\
\hline Gamma & Shape & 2.734 & 0.477 & 2.392 & 0.420 & 1.603 & 0.277 \\
\hline & Rate & 0.009 & 0.002 & 0.010 & 0.002 & 0.010 & 0.002 \\
\hline Lognormal & Log Mean & 5.563 & 0.097 & 5.274 & 0.101 & 4.755 & 0.126 \\
\hline & Log Standard Deviation & 0.710 & 0.068 & 0.743 & 0.072 & 0.929 & 0.089 \\
\hline Exponential & Rate & 0.003 & 0.0003 & 0.004 & 0.001 & 0.006 & 0.001 \\
\hline Cauchy & Location & 278.360 & 21.078 & 224.430 & 18.018 & 118.167 & 12.057 \\
\hline
\end{tabular}




\begin{tabular}{|c|c|c|c|c|c|c|c|}
\hline & Scale & 97.707 & 17.666 & 80.318 & 13.811 & 57.868 & 10.481 \\
\hline \multirow[t]{3}{*}{ Logistic } & Location & 303.707 & 22.942 & 231.794 & 19.039 & 145.790 & 15.958 \\
\hline & Scale & 96.774 & 10.925 & 80.894 & 9.269 & 67.984 & 7.863 \\
\hline & & Srimangal & & Ishurdi & & & \\
\hline \multirow[t]{2}{*}{ Normal } & Mean & 198.056 & 14.871 & 139.167 & 14.606 & & \\
\hline & Standard deviation & 109.281 & 10.516 & 107.334 & 10.328 & & \\
\hline \multirow[t]{2}{*}{ Weibull } & Shape & 1.919 & 0.196 & 1.432 & 0.139 & & \\
\hline & Scale & 223.972 & 16.783 & 153.811 & 15.436 & & \\
\hline \multirow[t]{2}{*}{ Gamma } & Shape & 3.278 & 0.593 & 2.039 & 0.361 & & \\
\hline & Rate & 0.017 & 0.003 & 0.015 & 0.003 & & \\
\hline \multirow[t]{2}{*}{ Lognormal } & Log Mean & 5.128 & 0.081 & 4.671 & 0.114 & & \\
\hline & Log Standard Deviation & 0.594 & 0.057 & 0.838 & 0.081 & & \\
\hline Exponential & Rate & 0.005 & 0.001 & 0.007 & 0.001 & & \\
\hline \multirow[t]{2}{*}{ Cauchy } & Location & 172.044 & 10.630 & 114.697 & 7.145 & & \\
\hline & Scale & 53.882 & 10.310 & 35.552 & 6.579 & & \\
\hline \multirow[t]{2}{*}{ Logistic } & Location & 188.110 & 14.022 & 123.275 & 10.769 & & \\
\hline & Scale & 59.439 & 6.773 & 47.508 & 5.608 & & \\
\hline
\end{tabular}

Based on AIC and BIC it is observed that the Weibull distribution for Mymensingh (AIC=678.31, $\mathrm{BIC}=682.29)$, Faridpur $(655.17,659.14)$, Chittagong $(683.59,687.57)$, Comilla $(662.28,666.26)$, Maijdi Court (702.21, 706.19), Cox's Bazar (708.34, 712.32), Bogra (643.36, 647.34), Khulna (649.26, 653.24), Satkhira (652.23, 656.21), Jessore $(643.54,647.52)$, Barisal $(677.01,680.99)$, and Sylhet $(685.78,689.76)$ and Gamma distribution for Ishurdi (631.91, 635.89), Rangpur (656.27, 660.25), Srimangal (652.46, 656.44), Dhaka (657.52, 661.49) are the best-fitted probability distributions for the post-monsoon rainfall data in Bangladesh (Table 5 and Table 6). Also the graphical comparisons of different probability distributions portrayed that the best-fitted distributions are the Weibull distribution for Mymensingh, Faridpur, Chittagong, Comilla, Maijdi Court, Cox's Bazar, Bogra, Khulna, Satkhira, Jessore, Barisal, and Sylheta and the Gamma distribution for the post-monsoon rainfall of the rest of the locations. The findings can be used for the future plan, welfare to mankind of the country. Therefore, getting the idea about the distribution of rainfall may help a lot in the policy-making decision in different sectors.

\subsection{Accuracy Measures - Goodness of Fit Statistic and Criteria}

The quality-of-fit of the probability distributions are tested by using the goodness-of-fit statistic the Anderson-Darling (AD), Cramer-von Mise (CvM), Kolmogorov-Smirnov (KS) and the best-fitted probability distribution for the post-monsoon rainfall data of the different locations are found to be based on the goodness-of-fit criterion for the maximum value of the log likelihood, the minimum value of Akaike information criterion (AIC), and the minimum value of Bayesian Information Criterion (BIC) (Table 5 and Table 6).

The parameters of the fitted probability distributions are estimated by the maximum likelihood estimation method. The Kolmogorov-Smirnov, Cramer-von Mises, and Anderson-Darling goodness of fit statistics are computed for the fitted probability distribution for the post-monsoon rainfall of different locations in Bangladesh and the best-fitted probability distributions are found for the minimum value of Akaike information criterion and Bayesian information criterion as the goodness of fit criteria.

Table 5. Goodness of Fit Statistics and goodness of fit criteria for different distributions for post-monsoon rainfall of 17 locations in Bangladesh

\begin{tabular}{|c|c|c|c|c|c|c|c|}
\hline \multirow{2}{*}{ Location } & \multirow{2}{*}{ Distribution } & \multicolumn{3}{|l|}{ Goodness-of-fit statistic } & \multicolumn{3}{|c|}{ Goodness-of-fit criteria } \\
\hline & & Kolmogorov-Smirnov & Cramer-von Mises & Anderson-Darling & Log-likelihood & AIC & $\mathrm{BIC}$ \\
\hline \multirow{7}{*}{ Mymensingh } & Normal & 0.1177 & 0.1263 & 1.0047 & -343.60 & 691.21 & 695.19 \\
\hline & Weibull & 0.1138 & 0.0980 & 0.6535 & -337.16 & 678.31 & 682.29 \\
\hline & Gamma & 0.1322 & 0.1363 & 0.8077 & -338.00 & 679.99 & 683.97 \\
\hline & Lognormal & 0.1657 & 0.3010 & 1.7736 & -342.77 & 689.54 & 693.52 \\
\hline & Exponential & 0.1586 & 0.3550 & 1.8666 & -341.39 & 684.78 & 686.77 \\
\hline & Cauchy & 0.1441 & 0.1207 & 1.0867 & -353.12 & 710.23 & 714.21 \\
\hline & Logistic & 0.0980 & 0.0803 & 0.8072 & -344.26 & 692.52 & 696.50 \\
\hline Faridpur & Normal & 0.1060 & 0.0702 & 0.5069 & -327.25 & 658.50 & 662.48 \\
\hline
\end{tabular}




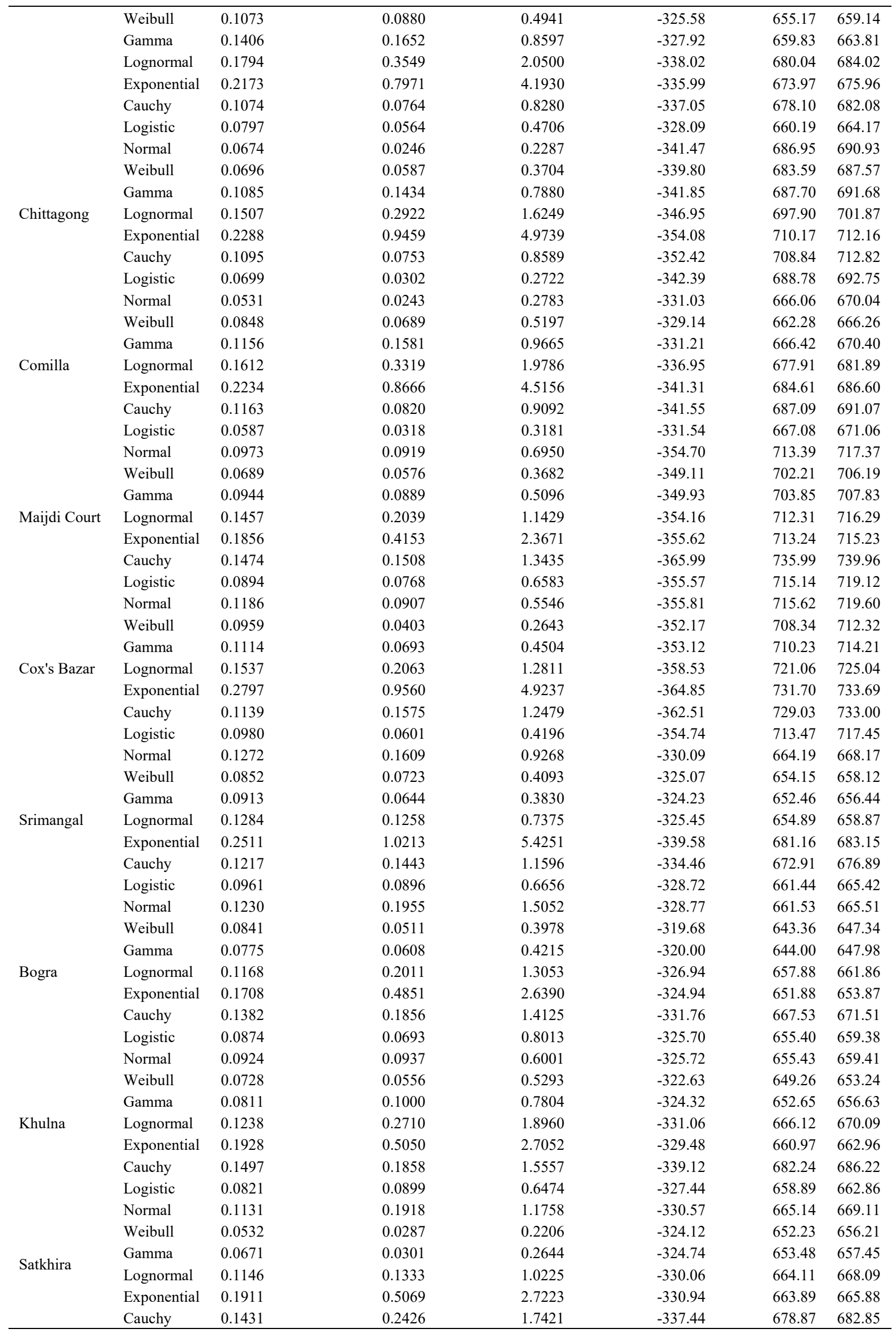




\begin{tabular}{|c|c|c|c|c|c|c|c|}
\hline \multirow{8}{*}{ Jessore } & Logistic & 0.0900 & 0.0999 & 0.8881 & -330.49 & 664.97 & 668.95 \\
\hline & Normal & 0.0886 & 0.0875 & 0.7863 & -326.03 & 656.07 & 660.05 \\
\hline & Weibull & 0.0764 & 0.0771 & 0.4677 & -319.77 & 643.54 & 647.52 \\
\hline & Gamma & 0.1004 & 0.1218 & 0.6641 & -320.39 & 644.78 & 648.76 \\
\hline & Lognormal & 0.1496 & 0.2672 & 1.4645 & -324.14 & 652.27 & 656.25 \\
\hline & Exponential & 0.1858 & 0.5082 & 2.7296 & -326.58 & 655.17 & 657.16 \\
\hline & Cauchy & 0.1375 & 0.1121 & 1.0401 & -333.82 & 671.64 & 675.62 \\
\hline & Logistic & 0.0860 & 0.0533 & 0.5595 & -325.41 & 654.82 & 658.80 \\
\hline \multirow{7}{*}{ Barisal } & Normal & 0.1048 & 0.0910 & 0.5472 & -339.69 & 683.39 & 687.36 \\
\hline & Weibull & 0.0851 & 0.0374 & 0.2644 & -336.51 & 677.01 & 680.99 \\
\hline & Gamma & 0.0843 & 0.0608 & 0.4285 & -337.87 & 679.74 & 683.72 \\
\hline & Lognormal & 0.1088 & 0.1594 & 1.0706 & -342.34 & 688.68 & 692.66 \\
\hline & Exponential & 0.2046 & 0.6616 & 3.6522 & -347.29 & 696.57 & 698.56 \\
\hline & Cauchy & 0.1418 & 0.1871 & 1.5443 & -352.66 & 709.32 & 713.30 \\
\hline & Logistic & 0.0976 & 0.0854 & 0.5919 & -341.32 & 686.64 & 690.62 \\
\hline \multirow{7}{*}{ Dhaka } & Normal & 0.1101 & 0.1455 & 1.0363 & -331.74 & 667.48 & 671.46 \\
\hline & Weibull & 0.0906 & 0.0609 & 0.4144 & -326.90 & 657.79 & 661.77 \\
\hline & Gamma & 0.0909 & 0.0662 & 0.3987 & -326.76 & 657.52 & 661.49 \\
\hline & Lognormal & 0.1298 & 0.1040 & 0.5685 & -328.01 & 660.03 & 664.00 \\
\hline & Exponential & 0.2097 & 0.7424 & 4.2531 & -339.50 & 681.00 & 682.99 \\
\hline & Cauchy & 0.1458 & 0.1717 & 1.4235 & -342.62 & 689.25 & 693.23 \\
\hline & Logistic & 0.0965 & 0.1010 & 0.8964 & -332.86 & 669.71 & 673.69 \\
\hline \multirow{7}{*}{ Rangamati } & Normal & 0.1110 & 0.1116 & 0.7302 & -333.09 & 670.18 & 674.16 \\
\hline & Weibull & 0.0717 & 0.0359 & 0.2412 & -329.06 & 662.11 & 666.09 \\
\hline & Gamma & 0.0640 & 0.0247 & 0.1405 & -328.07 & 660.15 & 664.12 \\
\hline & Lognormal & 0.0876 & 0.0459 & 0.2834 & -328.84 & 661.67 & 665.65 \\
\hline & Exponential & 0.2598 & 1.1286 & 6.0400 & -346.47 & 694.95 & 696.94 \\
\hline & Cauchy & 0.1421 & 0.1940 & 1.4865 & -341.56 & 687.13 & 691.11 \\
\hline & Logistic & 0.0846 & 0.0690 & 0.5730 & -332.82 & 669.63 & 673.61 \\
\hline \multirow{7}{*}{ Sylhet } & Normal & 0.1157 & 0.1317 & 0.9239 & -345.70 & 695.39 & 699.37 \\
\hline & Weibull & 0.0793 & 0.0609 & 0.3950 & -340.89 & 685.78 & 689.76 \\
\hline & Gamma & 0.1058 & 0.0899 & 0.5423 & -341.57 & 687.15 & 691.12 \\
\hline & Lognormal & 0.1401 & 0.2190 & 1.3012 & -345.40 & 694.80 & 698.78 \\
\hline & Exponential & 0.2141 & 0.7296 & 3.8118 & -350.84 & 703.69 & 705.68 \\
\hline & Cauchy & 0.1224 & 0.0889 & 0.8311 & -352.09 & 708.18 & 712.16 \\
\hline & Logistic & 0.0858 & 0.0544 & 0.6216 & -345.36 & 694.72 & 698.70 \\
\hline \multirow{7}{*}{ Ishurdi } & Normal & 0.2081 & 0.5757 & 3.2932 & -329.12 & 662.25 & 666.23 \\
\hline & Weibull & 0.1315 & 0.2296 & 1.3196 & -315.06 & 634.12 & 638.10 \\
\hline & Gamma & 0.1156 & 0.1677 & 0.9659 & -313.96 & 631.91 & 635.89 \\
\hline & Lognormal & 0.1501 & 0.2966 & 1.6551 & -319.28 & 642.57 & 646.54 \\
\hline & Exponential & 0.2254 & 0.7673 & 3.9561 & -320.53 & 643.05 & 645.04 \\
\hline & Cauchy & 0.0981 & 0.0740 & 0.6667 & -315.72 & 635.45 & 639.43 \\
\hline & Logistic & 0.1028 & 0.1410 & 1.3034 & -320.00 & 644.01 & 647.99 \\
\hline \multirow{8}{*}{ Rangpur } & Normal & 0.1784 & 0.3542 & 2.0411 & -338.40 & 680.80 & 684.78 \\
\hline & Weibull & 0.0866 & 0.0508 & 0.2936 & -326.25 & 656.49 & 660.47 \\
\hline & Gamma & 0.0727 & 0.0389 & 0.2468 & -326.14 & 656.27 & 660.25 \\
\hline & Lognormal & 0.1088 & 0.0970 & 0.6996 & -329.41 & 662.81 & 666.79 \\
\hline & Exponential & 0.1610 & 0.2520 & 1.4174 & -329.31 & 660.61 & 662.60 \\
\hline & Cauchy & 0.1528 & 0.2618 & 1.8990 & -339.51 & 683.03 & 687.00 \\
\hline & Logistic & 0.1149 & 0.1752 & 1.4527 & -336.67 & 677.34 & 681.32 \\
\hline & Normal & 0.1784 & 0.3542 & 2.0411 & -338.40 & 680.80 & 684.78 \\
\hline
\end{tabular}

The post-monsoon rainfall of the seventeen locations in Bangladesh provided the Weibull distribution as well fitted among the distributions for most of the locations and the rainfall of Dhaka, Ishurdi, Rangamati, Rangpur, and Srimangal are best fitted for Gamma distribution. The findings can be used for the future plan, welfare to mankind of the country. Therefore, getting the idea about the distribution of rainfall may help a lot in the policy-making decision in different sectors. 
CDFs (Mymensingh)

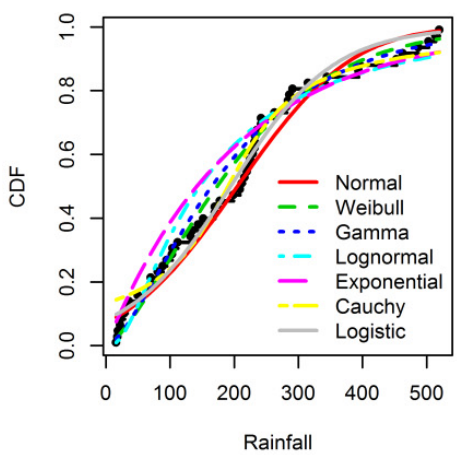

CDFs (Faridpur)

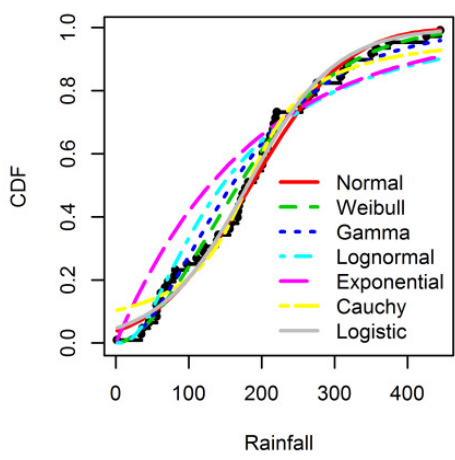

CDFs (Chittagong)

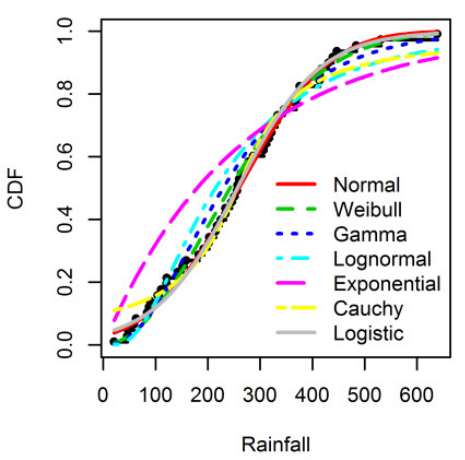

CDFs (Comilla)

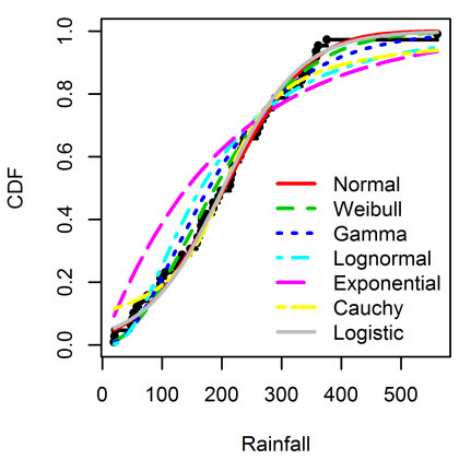

Densities (Mymensingh)

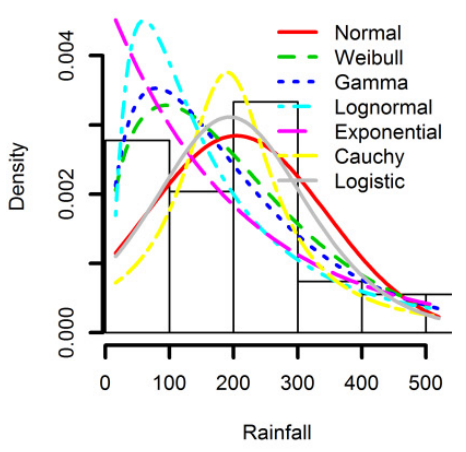

Densities (Faridpur)

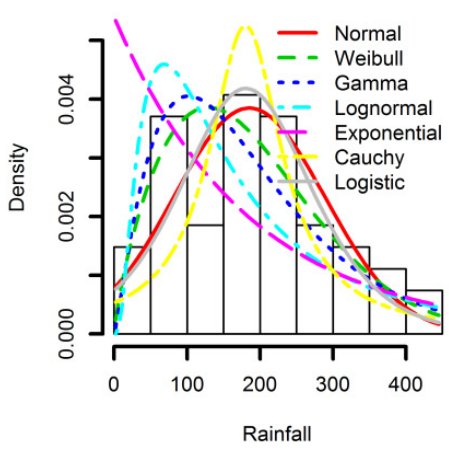

Densities (Chittagong)

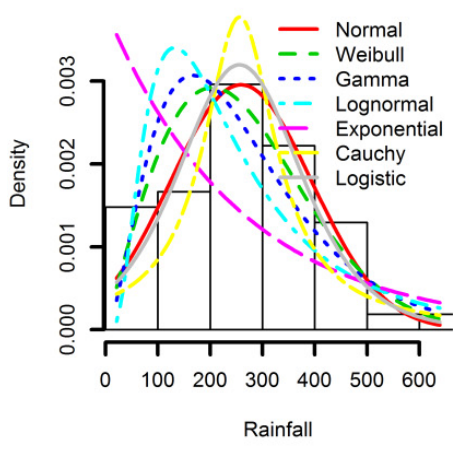

Densities (Comilla)

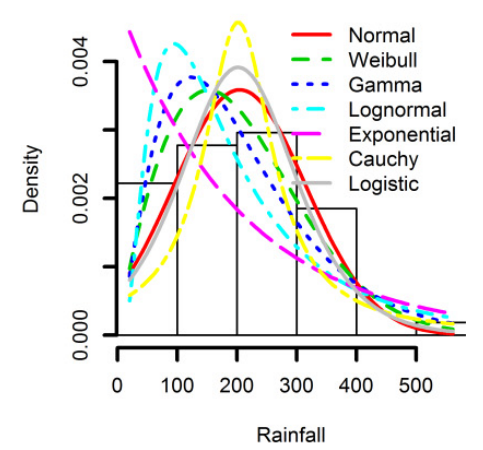

P-P Plot (Mymensingh)

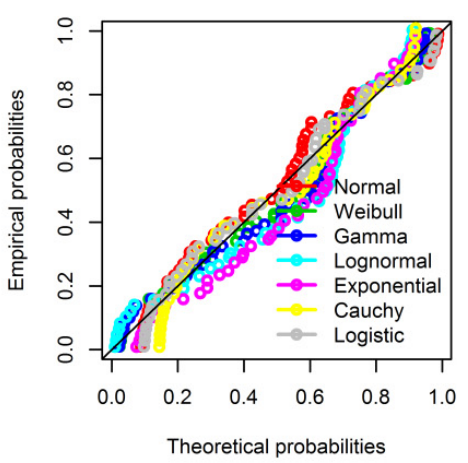

P-P Plot (Faridpur)

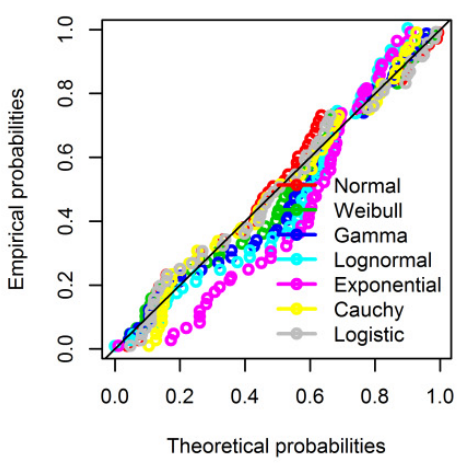

P-P Plot (Chittagong)

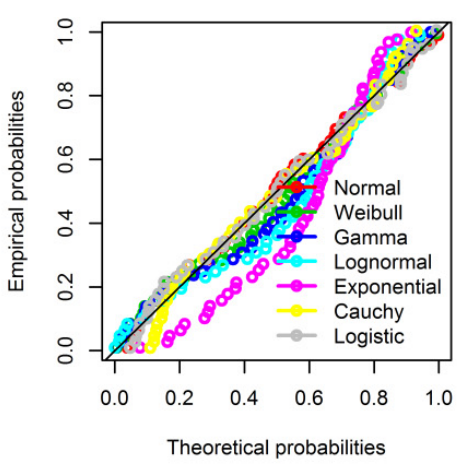

P-P Plot (Comilla)

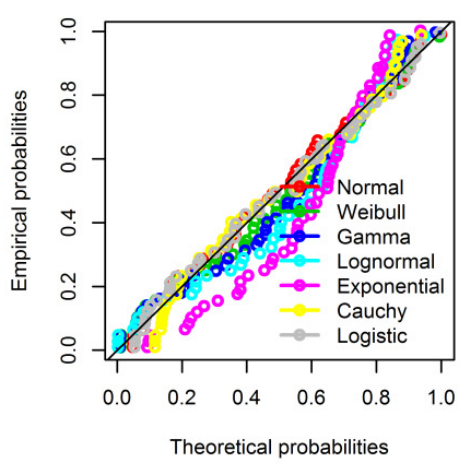

Figure 2. Cumulative Density Function, Histogram and Density Function, and P-P Plot of Post-Monsoon Rainfall for Mymensingh, Faridpur, Chittagong, and Comilla 
CDFs (Maijdi Court)

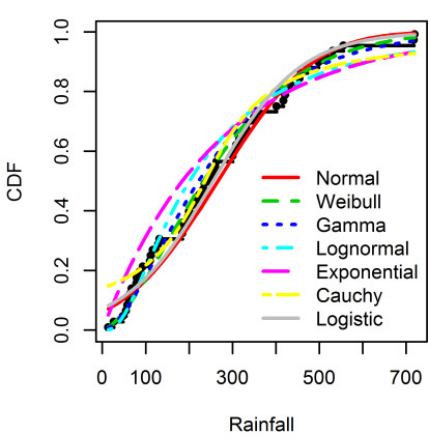

CDFs (Cox's Bazar)

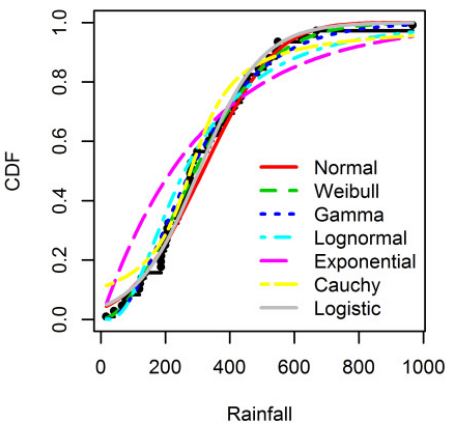

CDFs (Srimangal)

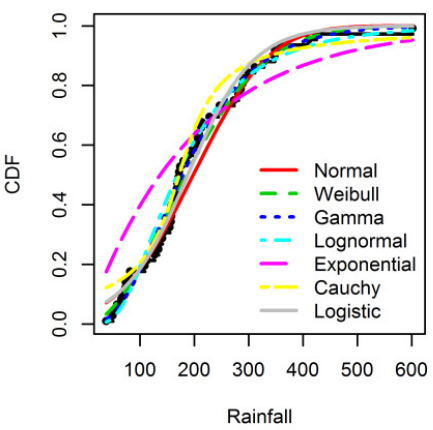

CDFs (Bogra)

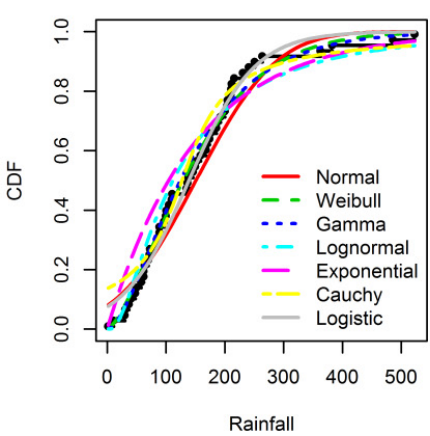

Densities (Maijdi Court)

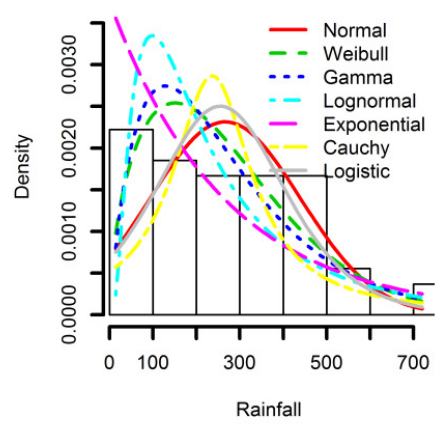

Densities (Cox's Bazar)

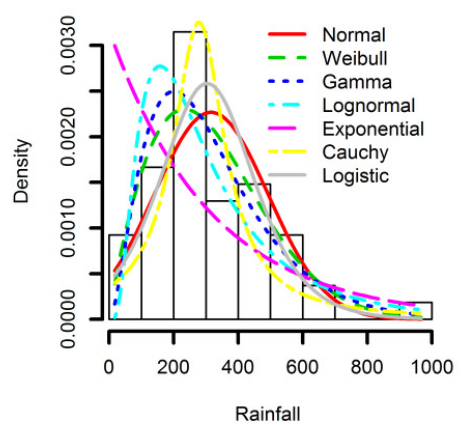

Densities (Srimangal)

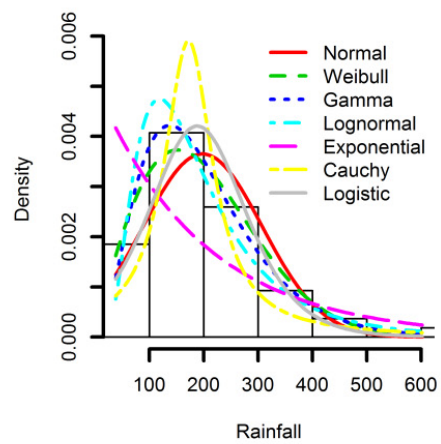

Densities (Bogra)

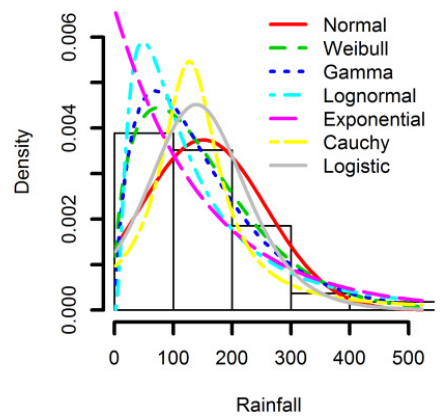

P-P Plot (Maijdi Court)

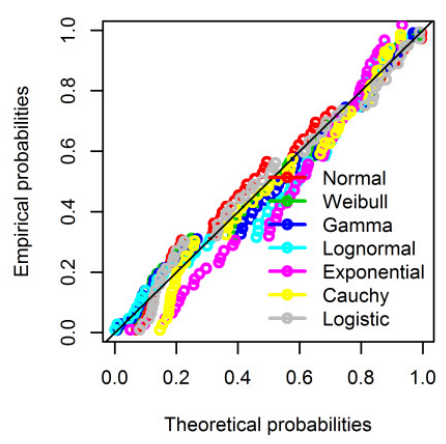

P-P Plot (Cox's Bazar)

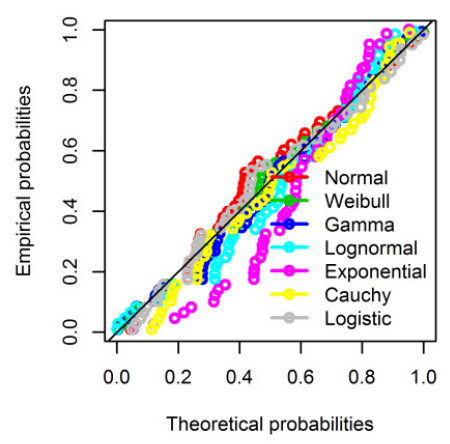

P-P Plot (Srimangal)

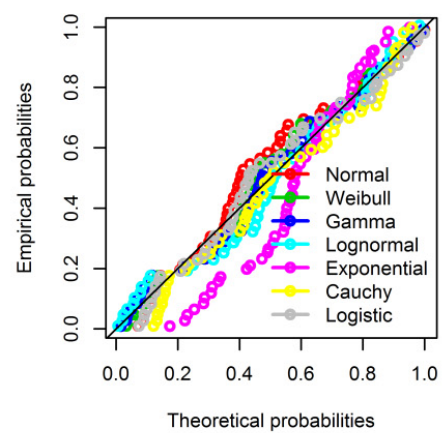

P-P Plot (Bogra)

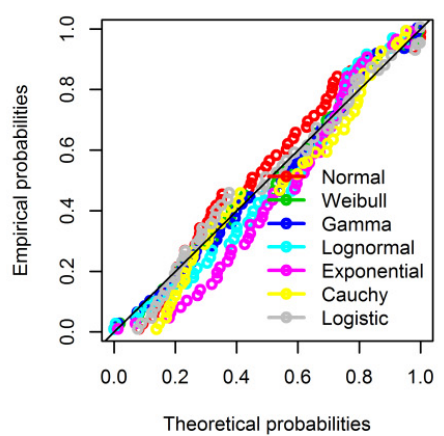

Figure 3. Cumulative Density Function, Histogram and Density Function, and P-P Plot of Post-Monsoon Rainfall for Maijdi Court, Cox’s Bazar, Srimangal, and Bogra 
CDFs (Khulna)

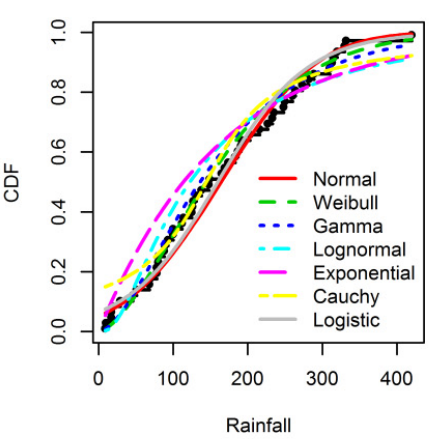

CDFs (Satkhira)

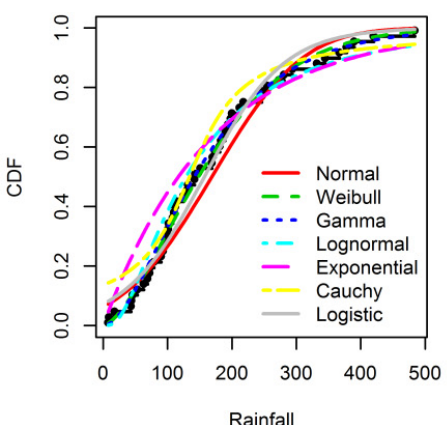

CDFs (Jessore)

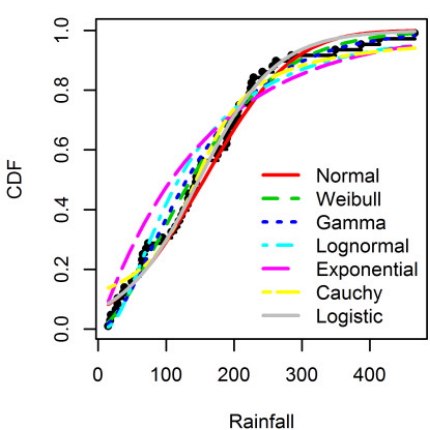

CDFs (Barisal)

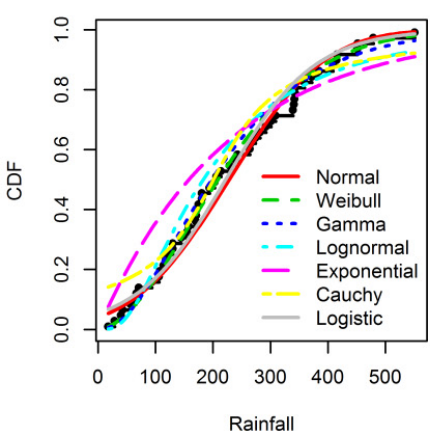

Densities (Khulna)

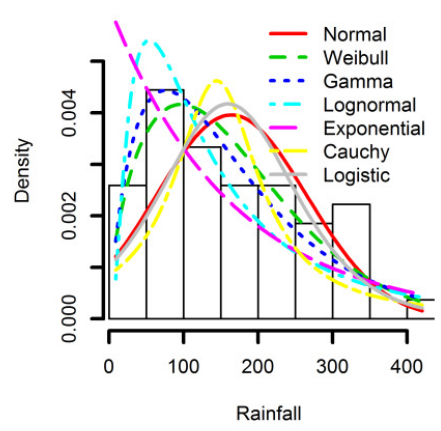

Densities (Satkhira)

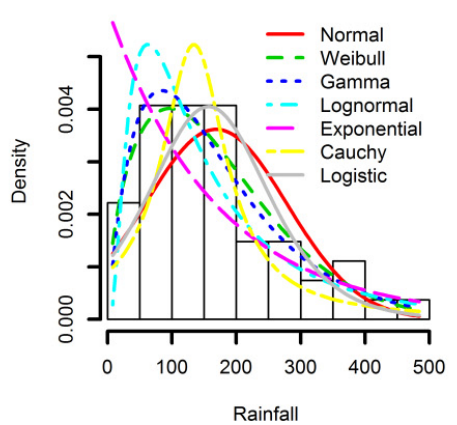

Densities (Jessore)

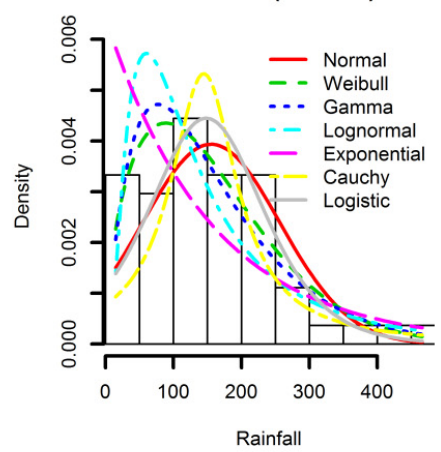

Densities (Barisal)

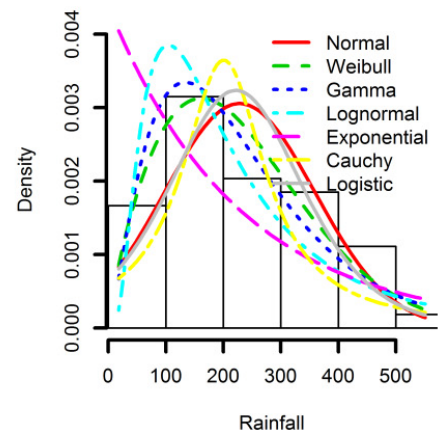

P-P Plot (Khulna)

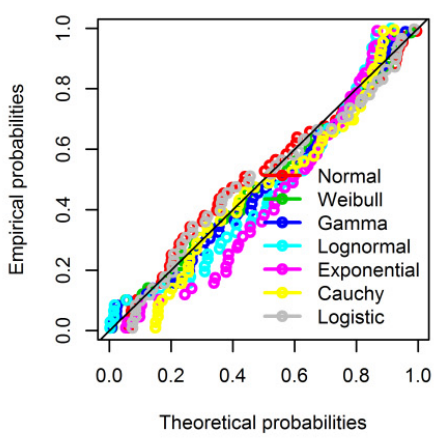

P-P Plot (Satkhira)

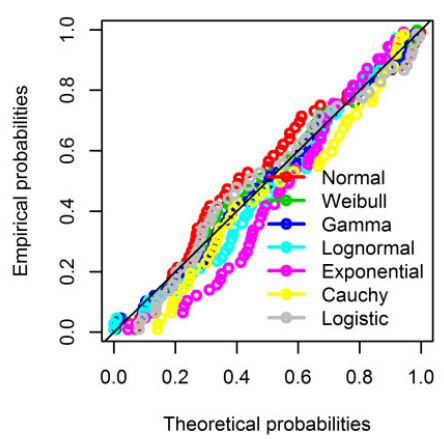

P-P Plot (Jessore)

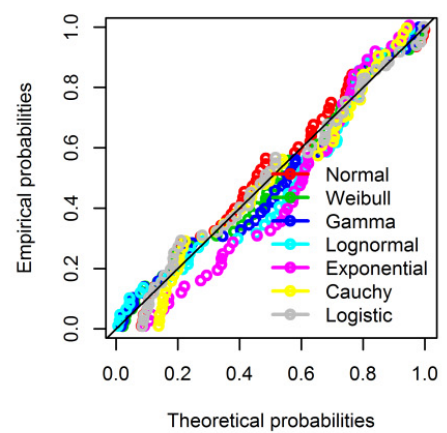

P-P Plot (Barisal)

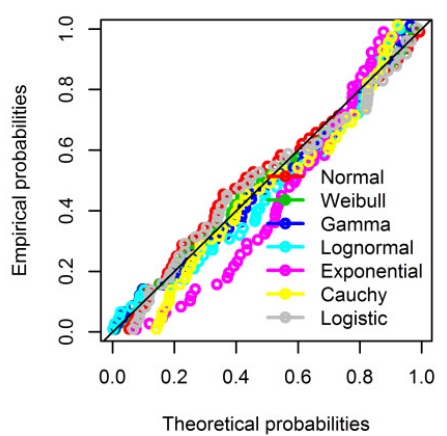

Figure 4. Cumulative Density Function, Histogram and Density Function, and P-P Plot of Post-Monsoon Rainfall for Khulna, Satkhira, Jessore, and Barisal 
CDFs (Dhaka)

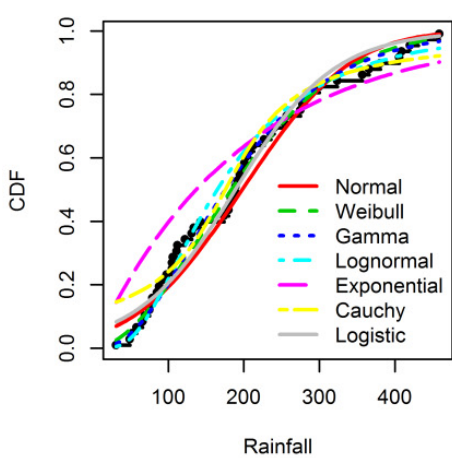

CDFs (Rangamati)

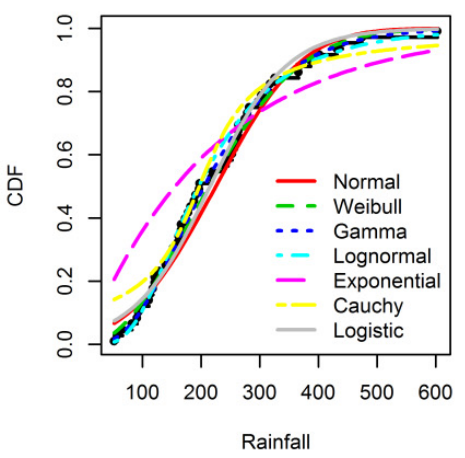

CDFs (Sylhet)

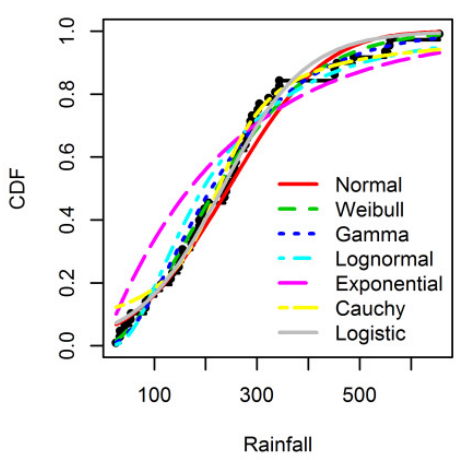

CDFs (Ishurdi)

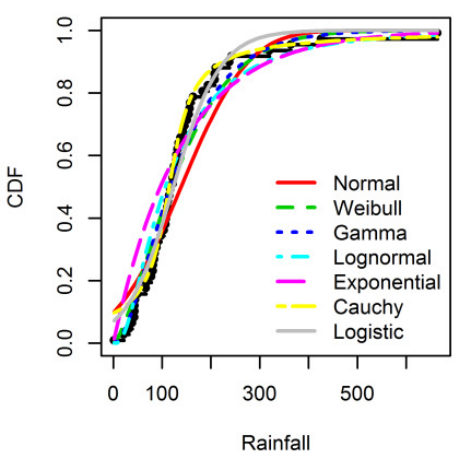

Densities (Dhaka)

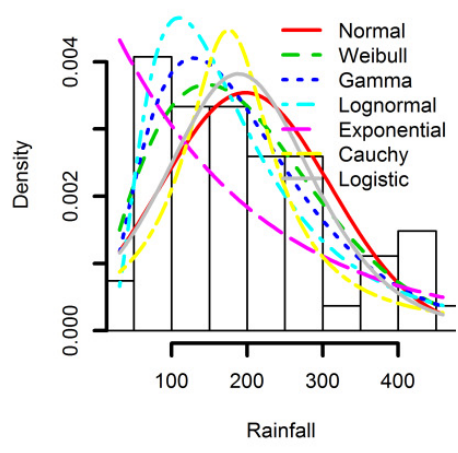

Densities (Rangamati)

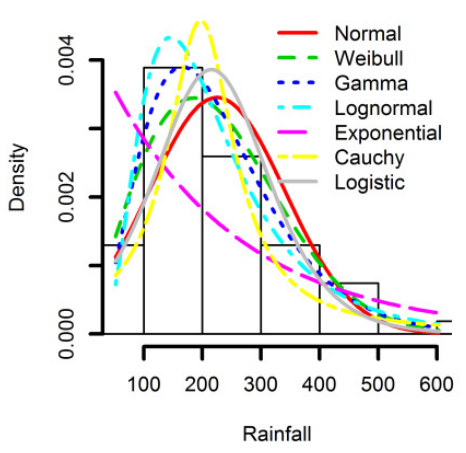

Densities (Sylhet)

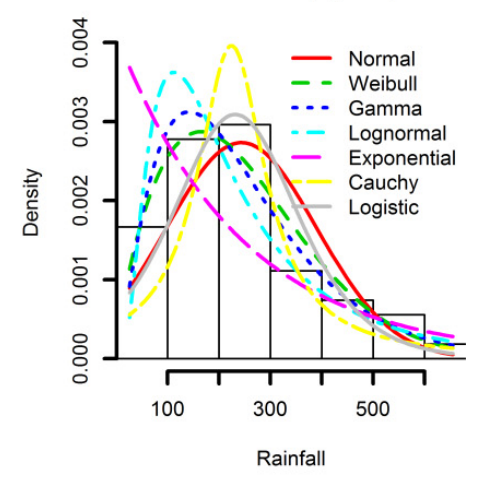

Densities (Ishurdi)

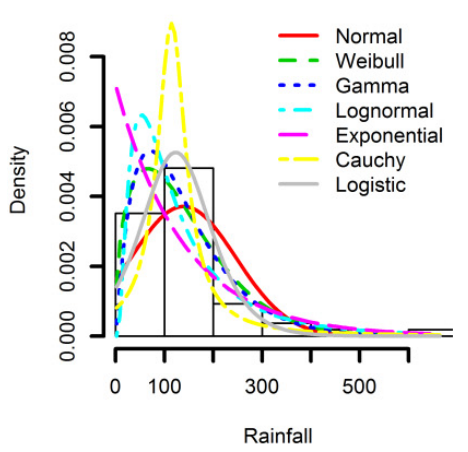

P-P Plot (Dhaka)

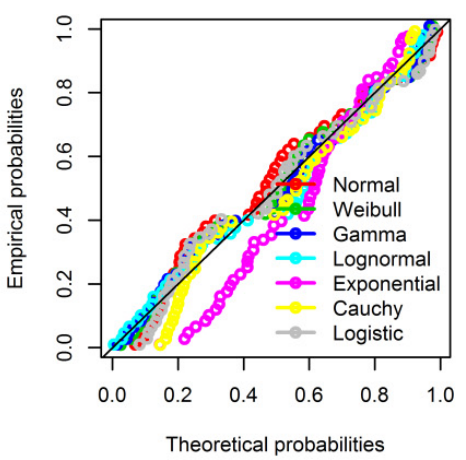

P-P Plot (Rangamati)

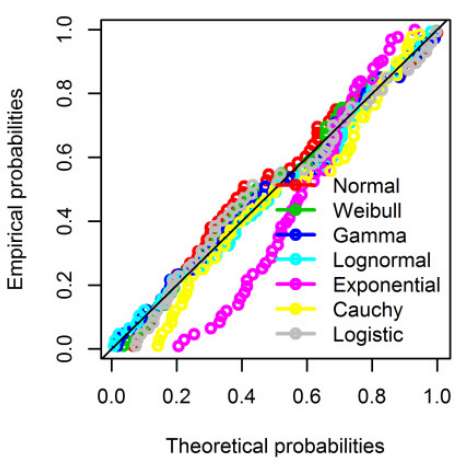

P-P Plot (Sylhet)

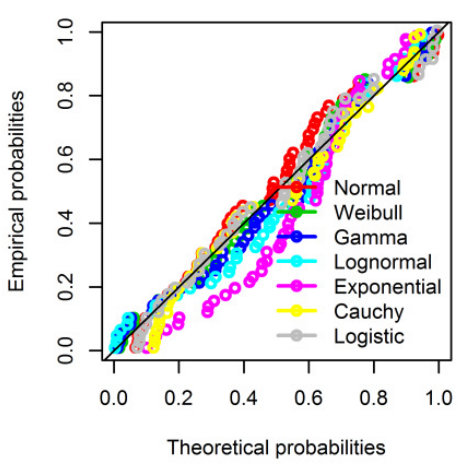

P-P Plot (Ishurdi)

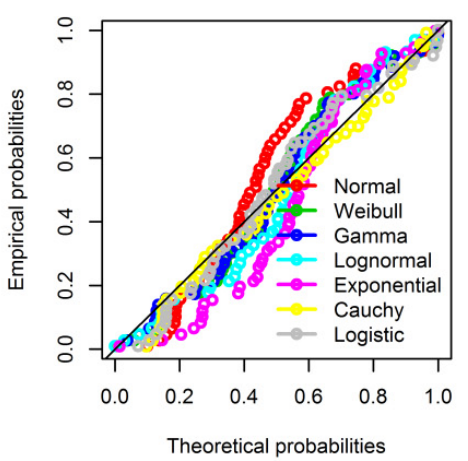

Figure 5. Cumulative Density Function, Histogram and Density Function, and P-P Plot of Post-Monsoon Rainfall for Dhaka, Rangamati, Sylhet, and Ishurdi 

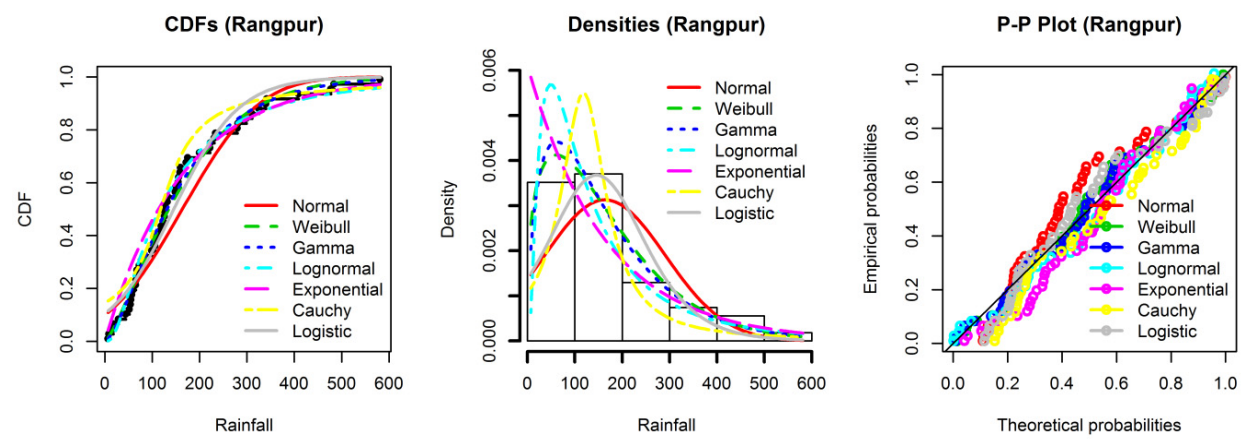

Figure 6. Cumulative Density Function, Histogram and Density Function, and P-P Plot of Post- Monsoon Rainfall for and Rangpur

Table 6 Best fitted distribution of post-monsoon rainfall of 17 locations in Bangladesh.

\begin{tabular}{|c|c|c|c|c|c|c|c|}
\hline \multirow[t]{3}{*}{ Location } & \multirow[t]{3}{*}{ Distribution } & \multicolumn{3}{|c|}{ Goodness-of-fit statistics } & \multicolumn{3}{|c|}{ Goodness-of-fit criteria } \\
\hline & & Kolmogorov & Cramer-von & Anderson & $\log$ & AIC & $\mathrm{BIC}$ \\
\hline & & -Smirnov & Mises & -Darling & likelihood & & \\
\hline Mymensingh & Weibull & 0.1138 & 0.0980 & 0.6535 & -337.16 & 678.31 & 682.29 \\
\hline Faridpur & Weibull & 0.1073 & 0.0880 & 0.4941 & -325.58 & 655.17 & 659.14 \\
\hline Chittagong & Weibull & 0.0696 & 0.0587 & 0.3704 & -339.80 & 683.59 & 687.57 \\
\hline Comilla & Weibull & 0.0848 & 0.0689 & 0.5197 & -329.14 & 662.28 & 666.26 \\
\hline Maijdi Court & Weibull & 0.0689 & 0.0576 & 0.3682 & -349.11 & 702.21 & 706.19 \\
\hline Cox's Bazar & Weibull & 0.0959 & 0.0403 & 0.2643 & -352.17 & 708.34 & 712.32 \\
\hline Srimangal & Gamma & 0.0913 & 0.0644 & 0.3830 & -324.23 & 652.46 & 656.44 \\
\hline Bogra & Weibull & 0.0841 & 0.0511 & 0.3978 & -319.68 & 643.36 & 647.34 \\
\hline Khulna & Weibull & 0.0728 & 0.0556 & 0.5293 & -322.63 & 649.26 & 653.24 \\
\hline Satkhira & Weibull & 0.0532 & 0.0287 & 0.2206 & -324.12 & 652.23 & 656.21 \\
\hline Jessore & Weibull & 0.0764 & 0.0771 & 0.4677 & -319.77 & 643.54 & 647.52 \\
\hline Barisal & Weibull & 0.0851 & 0.0374 & 0.2644 & -336.51 & 677.01 & 680.99 \\
\hline Dhaka & Gamma & 0.0909 & 0.0662 & 0.3987 & -326.76 & 657.52 & 661.49 \\
\hline Rangamati & Gamma & 0.0640 & 0.0247 & 0.1405 & -328.07 & 660.15 & 664.12 \\
\hline Sylhet & Weibull & 0.0793 & 0.0609 & 0.3950 & -340.89 & 685.78 & 689.76 \\
\hline Ishurdi & Gamma & 0.1156 & 0.1677 & 0.9659 & -313.96 & 631.91 & 635.89 \\
\hline Rangpur & Gamma & 0.0727 & 0.0389 & 0.2468 & -326.14 & 656.27 & 660.25 \\
\hline
\end{tabular}

\section{Summary and Conclusion}

The minimum post-monsoon rainfall of different locations in this study is less than sixty ( $\mathrm{mm}$ ) and maximum rainfall is greater than $420(\mathrm{~mm})$ for the period of 1961-2014. The maximum post-monsoon rainfall found for Cox's Bazar at 1975 among 1961-2014. The seven distributions are fitted for post-monsoon rainfall of seventeen locations and the parameters are estimated using maximum likelihood method. On the basis of graphical assessment and goodness-of-fit criterion the Weibull distribution for Barisal, Bogra, Chittagong, Comilla, Cox's Bazar, Faridpur, Jessore, Khulna, Maijdi Court, Mymensingh, Satkhira, and Sylhet; the Gamma distribution for Dhaka, Ishurdi, Rangamati, Rangpur, and Srimangal are found to be the best fit probability distributions for the post-monsoon rainfall data considered for the 17 different locations in Bangladesh.

\section{Acknowledgement}

Author is greatly thankful to the Bangladesh Meteorological Department for providing the data necessary for this study. Also Author is thankful to the Jahangirnagar University and Bangladesh University Grant Commission for support the fund. The author especially thanks the Editor and anonymous reviewers for their valuable suggestions that improved the quality of this manuscript.

\section{References}

Arora M., Singh P., Goel N. K., \& Singh R. D. (2006). Spatial Distribution and Seasonal Variability of Rainfall in a Mountainous Basin in the Himalayan Region. Water Resources Management, 20, 489-508. doi: 10.1007/s11269-006-8773-4 
Bhakar, S.R., Bansal, A.N., Chhajed, N., \& Purohit, R.C. (2006). Frequency analysis of consecutive day's maximum rainfall at Banswara, Rajasthan, India. ARPN Journal of Engineering and Applied Sciences, 1(3), 64-67.

Deka, S., \& Borah, M. (2009). Distribution of Annual Maximum Rainfall Series of North east India. European Water Publications, 27/28, 3-14.

Delignette-Muller, M. L., \& Dutang, C. (2015). fitdistrplus: An R Package for Fitting Distributions. Journal of Statistical Software, 64(4),1-34.

Ghosh, S., Roy, M. K., Biswas, S. C. (2016). Determination of the Best Fit Probability Distribution for Monthly Rainfall Data in Bangladesh. American Journal of Mathematics and Statistics, 6(4), 170-174, doi: 10.5923/j.ajms.20160604.05

Hirose, H. (1994). Parameter Estimation in the Extreme-Value distributions using the Continuation Method. Information processing society of Japan, 35(9), 1674-1681.

Hossian, M.M., Abdulla, F., and Rahman, M. H. (2016). Selecting the Probability Distribution of Monthly MaximumTemperature of Dhaka (Capital City) in Bangladesh, Jahangirnagar University Journal of Statistical Studies, 33, 33-45.

Johnson, L. N., Kotz, S., \& Balakrishnan, N. (1994). Continuous univariate distributions. Vol. 1, Wiley Series in Probability and Mathematical Statistics: Applied Probability and Statistics (2nd ed.). New York: John Wiley \& Sons.

Lancaster H. O. (1966). Forerunners of the Pearson Chi-square. Australian Journal of Statistics, 8, 117-126.

Lee, C. (2005). Application of rainfall frequency analysis on studying rainfall distribution characteristics of Chia-Nan plain area in Southern Taiwan. Journal of Crop, Environment \& Bioinformatics, 2, 31-38.

Mahgoub, M.T., \& Ibrahim, A. A. A. (2016). Fitting Probability Distributions of Annual Rainfall in Sudan. SUST Journal of Engineering and Computer Sciences (JECS), 17(2), 14-39.

Nadarajah, S. (2005). The exponential Gumbel distribution with climate application. Environmetrics, 17(1), 13-23. doi: 10.1002/env.739

Nadarajah, S., \& Choi, D. (2007). Maximum daily rainfall in South Korea. J. Earth Syst. Sci., 116(4), $311-320$. doi:10.1007/s 12040-007-0028-0

Nadarajah, S., \& Withers, C. S. (2001). Evidence of trend in returns levels for daily rainfall in New Zealand. Journal of Hydrology New Zealand, 39, 155-166.

Rahman M. H. (2017). Clustering of Pre-monsoon Precipitation of Bangladesh - A Ward's Hierarchical Agglomerative Clustering Approach. Research \& Reviews: Journal of Statistics, 6(2), 1-7.

Rahman M. H., Matin M. A., \& Salma U. (2018). Analysis of precipitation data in Bangladesh through hierarchical clustering and multidimensional scaling. Theor Appl Climatol, 134, 689-705. https://doi.org/10.1007/s00704-017-2319-y

Rahman, M. R., \& Lateh, H. (2016). Meteorological drought in Bangladesh: assessing, analysing and hazard mapping using SPI, GIS and monthly rainfall data. Environ Earth Sci, 75, 1026. doi:10.1007/s12665-016-5829-5

Redano, A., \& Lorente, J. (1993). Modelling the spatial and temporal distribution of rainfall intensity at local scale. Theor Appl Climatol, 47(1), 25-32. https://doi.org/10.1007/BF00868893

Sharma, M.A., \& Singh, J.B. (2010). Use of Probability Distribution in rainfall Analysis. New York science Journal, 3(9), 40-49.

Weibull W. (1951). A statistical distribution function of wide applicability. J. Appl. Mech. Trans., ASME, 18(3), 293-297.

Zeileis, A., \& Windberger, T. (2014). Fitting and Testing Generalized Logistic Distributions, Package 'glogis', $C R A N$. Retrieved from https://cran.rproject.org/web/packages/glogis/glogis.pdf

\section{Copyrights}

Copyright for this article is retained by the author(s), with first publication rights granted to the journal.

This is an open-access article distributed under the terms and conditions of the Creative Commons Attribution license (http://creativecommons.org/licenses/by/4.0/). 